\title{
Avaliação e aprendizagem na educação superior
}

\author{
JOE GARCIA*
}

\section{RESUMO}

Este artigo apresenta uma análise teórica sobre as relaçôes entre avaliação e aprendizagem na educação superior. Tendo por base a perspectiva fornecida por um conjunto de pesquisas a respeito da avaliação no contexto do ensino universitário, analisamos a influência que as práticas de avaliação exercem sobre a abordagem dos alunos em relação à aprendizagem. Também exploramos o conceito de estilo de pensamento, fundamentados nos escritos de Sternberg (1997). Ao final, tecemos algumas consideraçôes acerca da importância das escolhas avaliativas exercidas pelos professores que atuam na graduação.

Palavras-chave: ensino superior, avaliação da aprendizagem.

\section{RESUMEN}

Este artículo presenta un análisis teórico sobre las relaciones entre evaluación y aprendizaje en la enseńanza superior. Teniendo como base la perspectiva suministrada por un conjunto de investigaciones sobre la evaluación en el contexto de la enseñanza universitaria, analizamos las influencias que las prácticas de evaluación ejercen sobre el abordaje de los alumnos en relación al aprendizaje. También exploramos el concepto de estilo de pensamiento, a partir de los escritos de Sternberg (1997). Al final, tejemos algunas consideraciones acerca de la importancia de las elecciones evaluativas realizadas por el profesor que se desempeña en la graduación.

Palabras clave: enseñanza superior, evaluación del aprendizaje.

* Professor do Programa de Pós-Graduação em Educação da Universidade Tuiuti do Paraná (joe@sul.com.br). 


\section{ABSTRACT}

This article presents a theoretical analysis of the relationship between assessment and learning in higher education. Based on the perspective provided by a set of research projects on assessment in higher education, we analyze the influence that assessment practices exert on the students' approach to learning. Also, we explore the concept of thinking styles, based on the writings by Sternberg (1997). Finally, we dedicate some thoughts to the importance of teachers' assessment choices at the undergraduate level.

Keywords: higher education, learning evaluation. 


\section{INTRODUÇÃO}

Um observador atento à mídia internacional, nas últimas duas décadas, por certo, percebeu importantes mudanças na educação superior, em diversos países. A Conferência Mundial sobre Educação Superior, realizada em Paris, pela Unesco, no final dos anos 90, afirmou um processo de transformação universitária em todo o mundo (Bernheim; Chaui, 2008, p. 27). O conhecimento na sociedade contemporânea e as expectativas das nações em relação a um futuro econômico desejado, por exemplo, têm exercido papéis importantes na produção dessas transformaçóes. De modo ainda mais amplo, esse movimento está relacionado às profundas mudanças sociais, econômicas e culturais, no qual a universidade é chamada a rever teorias, modelos, conceitos e práticas. Nesse cenário, destacamos a importância de investigar e repensar a avaliação da aprendizagem na educação superior.

No centro das mudanças na educação superior estaria o desafio de redesenhar o currículo, pois as mudanças ali configuradas indicariam a medida efetiva de transformação realizada em qualquer instituição universitária (Bernheim; Chaui, 2008 , p. 31). A arquitetura do currículo precisa considerar diversas questóes; entretanto desejamos, neste artigo, destacar e analisar a relação entre avaliação e aprendizagem. Conforme argumentamos mais adiante, as práticas avaliativas utilizadas pelos professores na graduação, por exemplo, podem influenciar o desenvolvimento dos estudantes.

Há outros avanços a serem introduzidos nos currículos da educação superior. Deseja-se, por exemplo, currículos capazes de delinear experiências de aprendizagem por meio das quais os estudantes cultivem o pensamento crítico e reflexivo, desenvolvam capacidades de elaboração teórico-conceitual, aprendam a resolver problemas complexos, e que elaborem competências coerentes às novas exigências do mundo do trabalho. Mas as transformaçóes desejadas no currículo devem incluir, entre outros itens, uma revisão nos fundamentos e nas práticas de avaliação da aprendizagem dos educandos desse nível de ensino.

As transformações na educação superior não podem ser separadas das mudanças nas ideias e práticas que a constituem, bem como dos sujeitos que ali encontramos. Além disso, uma vez que essas transformações precisam estar articuladas ao currículo, é importante considerar a centralidade das experiências de aprendizagem como são concebidas, desenvolvidas e avaliadas. Isso apresenta diversas implicaçóes, tais como repensar a própria noção de educação que norteia os currículos dos cursos na universidade e as diversas práticas pedagógicas exercidas pelos professores, entre elas a avaliação. 
No cenário amplo da investigação educacional, o debate sobre a avaliação da aprendizagem na educação superior precisa ainda ser ampliado e atrair um número maior de interlocutores. Tal como constatado por Chaves (2004, p. 2), apenas recentemente, na literatura educacional brasileira, têm surgido trabalhos que discutem esse tema. Embora esse debate esteja concentrado particularmente nas últimas duas décadas, as análises realizadas fornecem algumas liçôes importantes. Se desejamos que os estudantes desenvolvam um pensamento criativo e reflexivo, por exemplo, teremos de desenhar um currículo compatível com essa expectativa, o que implica não somente selecionar novos conteúdos e competências para serem trabalhados com os alunos, mas repensar de modo amplo os diversos aspectos do processo de ensino-aprendizagem, incluindo as práticas de avaliaçáo que estamos utilizando no ensino universitário.

A importância da avaliação no contexto das práticas educacionais é talvez uma marca de nossa época. Isso reflete a obrigatoriedade dessa prática nos projetos educacionais, em qualquer nível de ensino, bem como a complexidade das questóes sobre avaliação. Assim, por exemplo, como formar indivíduos capazes de elaboração teórico-conceitual, se nossas práticas de avaliação estiverem atentas somente à tarefa de classificar os estudantes em relação às suas capacidades de reter determinado conjunto de informaçóes factuais? A avaliaçáo da aprendizagem na educação superior, de modo geral, ainda deveria avançar das práticas focalizadas que Luckesi (1994) denominou de "verificação da aprendizagem". A avaliação precisa ser exercida como uma "produção de sentidos", o que não pode estar restrito à utilização de instrumentos que apenas explicam o passado (Dias Sobrinho, 2008, p. 194). Além disso, a avaliação precisa guardar relação com as finalidades sociais mais amplas da educação, com o que desejamos no futuro. Finalmente, a adesão a uma ou outra forma de avaliação necessita ser vista também como um ato moral, pois nossas escolhas qualificam o modo como vemos e interagimos com nossos alunos (Villas Boas, 2000, p. 150).

Transformar o currículo, desenhar experiências de aprendizagem e decidir sobre estratégias de avaliação representam alguns dos principais desafios com os quais convivem os professores universitários. Nesse sentido, há várias perguntas que devem ser consideradas em relação à avaliação. O que avaliar? Como avaliar? Quais os melhores métodos para avaliar a aprendizagem dos estudantes na graduação, considerando as diretrizes atuais para a educação superior? Certamente, há diversas formas de responder a cada uma delas. Tais escolhas sáo complexas e até mesmo subjetivas (Gerard, 2002), que envolvem muito mais que instrumentos e métodos, pois mobilizam valores e solicitam uma visão bastante ampla sobre $\mathrm{o}$ ato de educar. 
Tradicionalmente, as práticas de avaliação da aprendizagem na educação superior recaem sobre um conjunto limitado de escolhas. Geralmente, tais estratégias se concentram no uso de procedimentos da "avaliação somativa", exercidos ao final de determinado período ou unidade de ensino. Isso implica, por exemplo, a manutençáo de uma antiga e persistente cultura avaliativa que tende a destacar particularmente a utilização de provas escritas para avaliar o grau de aprendizagem dos alunos. Além disso, esse reducionismo parece alterar a percepção dos professores quanto à variedade de atividades que podem ser envolvidas na avaliação, tendo em mente inferir o desempenho dos estudantes (Depresbiteris, 2004, p. 54). Também poderíamos questionar se a insistência na utilização da avaliação somativa tem-se mostrado efetivamente produtiva na educação superior.

É interessante considerar que as formas predominantes de avaliação da aprendizagem na educação superior refletem não somente as escolhas pedagógicas exercidas pelos professores, mas também as diretrizes curriculares dos cursos universitários, ou, ainda, de modo mais amplo, a própria cultura institucional que os influencia. Repensar a avaliação nesse cenário, portanto, é um desafio complexo, que reúne diversas questóes e perspectivas a serem analisadas. Neste artigo, entretanto, desenvolvemos uma elaboração teórica circunscrita a uma direção determinada. Tendo por base algumas investigaçóes sobre a avaliação da aprendizagem na educação superior, analisamos a influência que exercem as práticas avaliativas utilizadas pelos professores sobre o desenvolvimento cognitivo dos estudantes.

O texto está organizado da seguinte forma: inicialmente exploramos algumas questóes sobre a avaliação e aprendizagem na educaçáo superior; em seguida, analisamos as relaçóes entre avaliação e abordagem de aprendizagem, e estilos de pensamento; ao final, apresentamos algumas considerações sobre a importância das escolhas avaliativas dos professores que atuam na graduação.

\section{RELAÇÕES ENTRE AVALIAÇÃO E APRENDIZAGEM}

Há vários níveis de relacionamento entre avaliação e aprendizagem. Diversos estudos sobre a avaliação da aprendizagem na educação superior sugerem a existência de uma relação estreita entre as práticas de avaliação exercidas pelos professores e os diferentes níveis de desenvolvimento dos estudantes no decorrer da graduação. Tais práticas podem influenciar, por exemplo, a natureza das experiências de aprendizagem experimentada pelos alunos, como eles se envolvem com os estudos, que conhecimentos são importantes e como se veem no ensino universitário (Brown; Bull; Pendlebury, 1997, p. 7). 
Um aspecto central do desenvolvimento cognitivo e social durante a vida acadêmica, na graduação, reside justamente em "tornar-se estudante", tendo em vista, inclusive, conquistar espaço e sucesso dentro da comunidade de determinado curso. Nesse processo, os estudantes recebem a influência de diversas fontes e forças modeladoras, que atuam em seu desenvolvimento cognitivo, bem como em outros aspectos relacionados ao modo como experimentam e se adaptam às expectativas da vida acadêmica. Entre elas, destacamos as experiências avaliativas a que são submetidos na graduação.

Com base na análise de várias publicaçóes de pesquisa, a respeito da avaliação na educação superior, no período entre 1980 e 2002, Struyven, Dochy e Janssens (2005) argumentam que a avaliação exerce importante influência sobre a aprendizagem dos estudantes. De um lado, as expectativas em relação às estratégias avaliativas utilizadas pelos professores determinam o modo como eles lidam com as tarefas acadêmicas e se preparam para as atividades de avaliação. Em complemento, as experiências de avaliação proporcionadas aos estudantes influenciam suas atitudes futuras em relação à aprendizagem.

As experiências de avaliação são parte importante do currículo, não só na educação superior como nos demais níveis educacionais. É possível afirmar que tais experiências avaliativas são formativas sob diversos aspectos. Elas podem influenciar o modo como os estudantes planejam e utilizam o tempo dos estudos, atribuem prioridade e significado às diversas tarefas acadêmicas, e, de modo amplo, como eles se desenvolvem academicamente. Além disso, quando expostos à cultura avaliativa de determinado curso, e, portanto, sujeitos às rotinas, prioridades e conhecimentos atrelados a determinadas formas de avaliação, os estudantes tendem a desenvolver atitudes e práticas em relação à aprendizagem.

Há uma conexão delicada entre o engajamento dos estudantes e suas visóes sobre a avaliação na educação superior. Alguns estudos mostraram que o modo como os estudantes tomam notas é influenciado pelas expectativas quanto às formas de avaliação utilizadas pelos professores (Rickards; Friedman, 1978; Nolen; Haladyna, 1990). As pesquisas de Ramsden $(1997,1981)$ sugerem que pode haver perda na qualidade das experiências de aprendizagem de estudantes universitários, em razão de métodos de avaliação inapropriados e da carga excessiva de tarefas acadêmicas, o que também encorajaria atitudes superficiais de aprendizagem.

De modo amplo, pode-se afirmar que existe relação entre as formas de avaliação adotadas pelos professores e as atitudes de aprendizagem apresentadas pelos alunos na graduação. Diferentes tipos de avaliação tendem a determinar a atitude de apren- 
dizagem dos estudantes; entretanto, ela seria dinâmica e modificável, em função do contexto de aprendizagem e das práticas avaliativas experimentadas pelos estudantes (Struyven; Dochy; Janssens, 2005, p. 333). Isso destaca o importante papel dos professores, que podem influenciar a abordagem de aprendizagem adotada pelos estudantes. No entanto, o conhecimento a respeito das formas como os professores podem melhor orientar os alunos quanto a suas abordagens de aprendizagem depende ainda de muita investigação.

$\mathrm{Na}$ próxima seção, avançamos nossa análise, explorando as relaçôes entre as práticas de avaliação adotadas pelos professores e as abordagens de aprendizagem assumidas pelos alunos.

\section{AVALIAÇÃO E ABORDAGENS DE APRENDIZAGEM}

Os estudos sobre as abordagens dos estudantes em relação à aprendizagem iniciaram-se formalmente com a pesquisa realizada, há algumas décadas, por Marton e Säljö (1976). Nesse estudo, eles observaram o modo como um grupo de estudantes lidava com a tarefa que envolvia a leitura de um texto acadêmico, tendo em vista responder a determinado conjunto de perguntas sobre ele.

Segundo esses pesquisadores, duas formas distintas de abordagem dessa experiência de aprendizagem foram observadas. Parte dos alunos adotou a abordagem de aprendizagem focalizada na compreensão do texto como um todo. A outra parte do grupo assumiu uma abordagem focalizada na memorizaçáo e reproduçáo de conteúdos factuais do texto, que supostamente seriam perguntados mais tarde. Essas duas abordagens originaram os conceitos de "abordagem profunda" e "abordagem de superfície" em relação à aprendizagem. A seguir consideramos cada uma delas.

A "abordagem profunda" envolve o esforço efetivo de análise e compreensão de conceitos e princípios, por exemplo, subjacentes ao material de estudo e estaria mais relacionada à aprendizagem autêntica, bem como articulada ao modo de lidar com situaçóes-problema em contextos novos e mais próximos da atuação profissional além dos estudos da graduação. Essa noçáo também se refere ao modo de interagir com conteúdos de aprendizagem como meios para compreender mais profundamente os significados a eles subjacentes.

A "abordagem de superfície” estaria relacionada a uma atitude mais passiva de aceitação das informações fornecidas pelos professores e materiais didáticos, bem como à memorização de conteúdos factuais, desarticulada de compreensão efetiva e retenção de longo termo. Por meio dessa abordagem, os estudantes interagem com os conteúdos curriculares para obter aquilo que lhes parece necessário aprender, 
tendo em vista determinada atividade ou forma de avaliação, mas sem a intenção de relacionar os conhecimentos estudados a uma perspectiva conceitual mais ampla (Snow; Corno; Jackson, 1996, p. 282).

A aprendizagem profunda se refere a certas práticas de ensino que priorizam a autonomia dos estudantes, os processos interpretativos e a elaboração conceitual. Além disso, haveria relação entre esse estilo de aprendizagem e a motivação intrínseca. A aprendizagem superficial, por seu turno, estaria relacionada a práticas de ensino mais diretivas, que priorizam a memória e nas quais os estudantes assumem papéis mais passivos.

Algumas estratégias de avaliação solicitam aos estudantes que forneçam determinados tipos de resposta, que atendam a critérios de objetividade, que possam ser previstas e, portanto, articuladas em uma pergunta, tal como nos testes de múltipla escolha. Esse tipo de avaliação, comumente realizada sob a perspectiva somativa, tem por objetivo distinguir o conhecimento objetivo e factual, e atende melhor as expectativas de uma aprendizagem superficial.

Mas a avaliaçáo pode ser "profunda", no sentido de envolver procedimentos e pressupostos que têm em mente outro nível de aprendizagem. Nesse caso, as atividades de avaliação podem solicitar, por exemplo, que os estudantes desenvolvam compreensão conceitual e análise interpretativa, a fim de explorar diferentes perspectivas sobre determinado contexto ou conjunto de dados. Esse tipo de experiência de avaliação encoraja os estudantes a explorar uma gama ampla de habilidades cognitivas, por meio de atividades que envolvem a aprendizagem contextualizada e situaçôes autênticas. Isso ocorre em avaliações de natureza formativa, como o trabalho com estudo de caso, portfólio, mapas conceituais e resolução de problemas.

As pesquisas sobre as atitudes dos alunos em relação à aprendizagem e o debate sobre suas implicaçóes para o desenho de novas práticas pedagógicas vêm avançando há décadas. Se, de um lado, observamos, entre os teóricos, o argumento de que deveríamos transformar e avançar as práticas de ensino de forma a adaptá-las às abordagens de aprendizagem dos alunos, por outro, há uma preocupação relacionada à influência exercida pelas práticas avaliativas acerca de como os alunos decidem por determinada abordagem de aprendizagem.

Segundo as pesquisas realizadas por Marton e Säljo (1997), a percepção dos estudantes, quanto às práticas de avaliação dos professores, apresenta forte relação com a abordagem de aprendizagem que aqueles adotam quando se dedicam a uma tarefa acadêmica. Os estudos de Biggs (1999) e Cowman (1998) sugerem que as formas de avaliação exercidas pelos professores influenciam as abordagens 
de aprendizagem que os alunos desenvolvem na graduação. Biggs (1999) mostrou que o formato das atividades de avaliação definidas pelos professores vão encorajar os estudantes a utilizar determinadas abordagens de aprendizagem. A pesquisa realizada por Cowman (1998) revela, por exemplo, que as atitudes dos estudantes em relação à aprendizagem estavam diretamente relacionadas às suas interpretaçóes sobre as atividades de avaliação. Isso sugere que as formas como os estudantes são avaliados nos cursos de graduação podem exercer uma influência modeladora não somente sobre seus desempenhos, mas sobre a formação de suas atitudes em relação à aprendizagem (Struyven; Dochy; Janssens, 2005, p. 332).

Outras pesquisas apontam que as práticas pedagógicas dos professores universitários têm impacto sobre as crenças dos alunos a respeito da aprendizagem, e influenciam os resultados obtidos por eles (Northcote, 2003). Um estudo realizado por Eklund-Myrskog (1998) indicou que, tal como observado em outros levantamentos, as concepçôes de aprendizagem dos estudantes estáo relacionadas aos contextos educacionais a que são expostos, incluindo as práticas de avaliação. A pesquisa desenvolvida por Entwistle e Tait (1990) assinalou que a abordagem profunda em relação à aprendizagem estaria relacionada à percepção da relevância das atividades acadêmicas. Em complemento, haveria relaçáo entre a abordagem de superfície e a percepção de que a carga de trabalho solicitada pelos professores é muito pesada e pouco significativa.

O conjunto dessas pesquisas nos alerta sobre o impacto que exercem as práticas pedagógicas dos professores sobre o desenvolvimento dos estudantes na graduaçáo, particularmente no que diz respeito a suas aprendizagens. E aqui destacamos o papel exercido pelas decisóes dos professores relacionadas às formas de avaliação que utilizam com os alunos. Mas é interessante salientar que é a percepção dos estudantes sobre os elementos do ambiente de aprendizagem que determina como eles aprendem, e não necessariamente o contexto educacional em si (Struyven; Dochy; Janssens, 2005, p. 331). Isso parece sugerir a necessidade de os professores, na educaçáo superior, estarem atentos ao modo como os alunos percebem suas práticas avaliativas. Nesse sentido, uma das questóes a considerar, por exemplo, seria a importância dos educandos terem clareza quanto às finalidades dos métodos usados, bem como os critérios de avaliação praticados pelos professores.

\section{AVALIAÇÃO E ESTILOS DE PENSAMENTO}

Talvez acompanhando o clima de reforma educacional, a variedade de métodos de avaliação utilizados na educação superior tem-se ampliado nos últimos anos. Entre os métodos mais recentes destacamos o portfólio, e diversas formas de autoa- 
valiação e avaliação entre pares. Tais métodos solicitam não somente outras práticas dos professores, mas novas atitudes dos alunos em relação à aprendizagem e o exercício de determinados estilos de pensamento.

Há pouco mais de uma década, Richard Sternberg (1997), em seu livro Thinking Styles, apresenta interessante perspectiva para pensar a relação entre desenvolvimento cognitivo e avaliação dos estudantes na educação superior. $\mathrm{O}$ conceito de estilo de pensamento refere-se ao modo como um sujeito prefere usar suas habilidades (Sternberg; Zhang, 2005). Não é, portanto, uma habilidade em si mesma.

Sternberg argumenta, a propósito das relaçóes entre estilos de aprendizagem e a educação, que o modo como os estudantes desenvolvem suas inteligências, seus "estilos de pensamento", seria influenciado pelas expectativas institucionais. Assim, o sucesso de um estudante na universidade estaria relacionado à habilidade de se "adaptar" ou "conformar" ao estilo predominante de pensamento institucional. Nesse sentido, um bom desempenho na vida acadêmica refletiria, de forma significativa, a capacidade de os estudantes se adaptarem às expectativas de "estilos de pensamento", evidenciadas no modo como os professores ensinam e como avaliam. Os alunos perceberiam na avaliação uma mensagem não somente sobre o que deveriam aprender, mas como deveriam pensar.

Os argumentos apresentados por Sternberg (1997) fornecem uma perspectiva com muitas questôes a considerar. A relação entre avaliação e aprendizagem seria tal que a natureza da aprendizagem, experimentada pelos estudantes, e seus estilos de pensamento poderiam ser bastante influenciados pelas estratégias de avaliaçáo utilizadas pelos professores. Isso torna importante náo somente o método escolhido pelo professor, mas também suas expectativas - o que tem em mente quando utiliza determinada forma de avaliação.

Desse modo, é significativa a recorrente preocupação dos estudantes no que diz respeito, por exemplo, ao "jeito" como supostamente os professores "gostam" da redação das respostas em uma prova escrita, ou da estrutura e do conteúdo de um trabalho. Nesse cenário, haveria relação entre o sucesso nas avaliaçóes e o conhecimento do "jeito" de demonstrar a aprendizagem preferido pelos professores, ou que é destacado na cultura de um curso. Mas essa abordagem também pode nos ajudar a pensar as razóes do fracasso dos estudantes na graduação. $\mathrm{O}$ fracasso poderia resultar não apenas da ausência de inteligência ou da capacidade para aprender, mas da falta de compatibilidade entre os estilos de pensamento de determinados alunos em relação àqueles destacados ou solicitados pelos professores - na forma como avaliam, por exemplo. 
Diante da leitura apresentada por Sternberg (1997), nos parece necessário repensar não somente as estratégias de avaliação utilizadas na educação superior, mas outras questóes articuladas às escolhas dos professores, o modo como são transmitidas aos estudantes, e as expectativas explicitadas, ou não, em suas práticas de avaliação. Enfim, deveríamos avançar nas discussôes sobre avaliação e formação de professores na educação superior.

\section{CONSIDERAÇÕES FINAIS}

Exploramos neste artigo um conjunto de questóes sobre avaliação e aprendizagem na educação superior, destacando a importância das escolhas realizadas pelos professores. Tendo por base alguns estudos que conectam avaliação e aprendizagem, argumentamos que as práticas de avaliação exercidas pelos professores apresentam diversas implicaçóes sobre as atitudes de aprendizagem mostradas pelos estudantes. Assim, por exemplo, quando os professores optam por avaliar a aprendizagem dos alunos por meio de provas escritas, ao final do bimestre, eles estabelecem algumas condiçóes, projetam expectativas e desenham um quadro a ser interpretado pelos estudantes. Tal interpretação reflete-se no modo de agir dos estudantes em sala de aula - como diferenciam conteúdos do currículo e desenvolvem hábitos de estudo - e, de modo mais amplo, na aprendizagem, que exerce papel considerável em suas formaçóes.

As escolhas exercidas pelos professores podem ampliar ou limitar as oportunidades para que os estudantes demonstrem o que aprenderam. Além disso, as práticas de avaliação podem ser mais ou menos restritivas em relação à possibilidade de fornecer feedback ao aluno sobre seu desempenho durante o processo de ensinoaprendizagem. Tais aspectos são fundamentais na atualidade, considerando a importância que as práticas de avaliação formativa vêm conquistando.

De acordo com o método de avaliação que os professores decidem utilizar, entram em cena determinadas expectativas, e são colocadas em ação estratégias próprias para verificar os resultados da aprendizagem dos estudantes. Além disso, diferentes métodos de avaliação são utilizados em momentos diferenciados do processo de ensino-aprendizagem, de acordo com os propósitos investigativos do professor. Assim, pode ser feita uma avaliação diagnóstica inicial, outra para acompanhar o desenvolvimento cognitivo do aluno em determinado espaço de tempo, ou ainda ter caráter somativo, realizada ao final do período de aprendizagem.

Neste texto, exploramos algumas possíveis relaçóes entre as escolhas avaliativas dos professores e a aprendizagem dos alunos. Seja qual for a prática avaliativa do professor, e mesmo que sua escolha lhe pareça trivial, ela será um marco de referên- 
cia para a abordagem de aprendizagem dos estudantes. Os esforços a serem empreendidos, a estratégia de estudo e os conteúdos a serem priorizados, seráo decididos com base em suas percepçóes sobre aquela escolha, o que faz com que a avaliação exerça destacada influência sobre a aprendizagem dos estudantes - embora não seja isso o desejado pelos professores.

Uma pergunta recorrente entre muitos docentes reside em qual a melhor forma de avaliar os estudantes. Essa pergunta é complexa, e não se resume em considerar quais métodos podem ser utilizados, segundo apenas suas características. Essa escolha precisa levar em conta tanto o tipo de aprendizagem que queremos adotar quanto as possíveis respostas dos alunos a ela. Diversas pesquisas sugerem que, mesmo conhecendo muito sobre as características e formas de aplicação de diversos métodos de avaliação na educação superior, ainda não sabemos o suficiente a respeito de como conseguir, de maneira sistemática, que os estudantes experimentem determinadas formas de aprendizagem. Há muitas perguntas ainda a fazer, e respostas a obter.

Existe uma última questão a destacar. É fundamental que os professores avancem no estudo da avaliação e suas relaçóes com a aprendizagem. Mas não se trata apenas de aprofundar o domínio teórico sobre os diversos métodos hoje disponíveis na literatura educacional. Tendo em perspectiva o horizonte das questóes e pesquisas apresentadas neste artigo, salientamos a importância dos educadores refletirem sobre suas práticas avaliativas, considerando a profunda influência que estas exercem sobre a aprendizagem dos alunos. As escolhas avaliativas dos professores, afinal, são capazes de moldar os trajetos de aprendizagem dos estudantes, e, portanto, de transformar a natureza de suas experiências educacionais na graduação. Esta é uma tarefa complexa, sem dúvida, mas também fundamental, tendo em vista as transformaçóes desejadas na educação superior.

\section{REFERÊNCIAS BIBLIOGRÁFICAS}

BERNHEIM, C. T.; CHAUI, M. Desafios da universidade na sociedade do conhecimento. Brasília: Unesco, 2008.

BIGGS, J. Teaching for quality learning at university. Buckingham: Open University Press, 1999.

BROWN, G.; BULL, J.; PENDLEBURY, M. Assessing student learning in higher education. London: Routledge, 1997.

CHAVES, S. Avaliação da aprendizagem no ensino superior: realidade, complexidade e possibilidades. In: REUNIÃO ANUAL ANPED,
270, 2002, Caxambu. Anais... Caxambu: Anped, 2004. p. 1-16.

COWMAN, S. The Approaches to learning of student nurses in the republic of Ireland and Northern Ireland. Journal of Advanced Nursing, v. 28, n. 4, p. 899-910, Oct. 1998.

DIAS SOBRINHO, J. Avaliação educativa: produção de sentidos com valor de formação. Avaliação, v. 13, n. 1, p. 193-207, 2008.

DEPRESBITERIS, L. Avaliação da aprendizagem: revendo conceitos e posições. In: SOUZA, C. (Org.). Avaliação do rendimento escolar. 12. ed. 
Campinas: Papirus, 2004. p. 51-79.

EKLUND-MYRSKOG, G. Students' conceptions of learning in different educational contexts. Higher Education, v. 35, n. 3, p. 299-316, 1998.

ENTWISTLE, N.; TAIT, H. Approaches to learning, evaluations of teaching, and preferences for contrasting academic environments. Higher Education, v. 19, n. 2, p. 169-194, June 1990.

GERARD, F. M. L'Indispensable subjectivité de l'évaluation. Antipodes, n. 156, p. 26-34, Avr. 2002.

LUCKESI, C. Avaliação da aprendizagem escolar. São Paulo: Cortez, 1994.

MARTON, F.; SÄLJÖ, R. Approaches to learning. In: MARTON, F.; HOUNSELL, D.; ENTWISTLE, N. (Ed.). The Experience of learning: implications for teaching and studying in higher education. Edinburgh: Scottish Academic Press, 1997. p. 39-59.

learning: outcome and process. British Journal of Educational Psychology, v. 46, p. 4-11, 1976.

NOLEN, S. B.; HALADYNA, T. Personal and environmental influences on students' beliefs about effective study strategies. Contemporary Educational Psychology, v. 15, n. 2, p. 116-130, 1990.

NORTHCOTE, M. On line assessment in higher education: the influence of pedagogy on the construction of students' epistemologies. Issues in Educational Research, v. 13, n. 1, p. 6684, 2003.

RAMSDEN, P. The Context of learning in academic departments. In: MARTON, F.;
HOUNSELL, D.; ENTWISTLE, N. (Ed.). The Experience of learning: implications for teaching and studying in higher education. Edinburgh: Scottish Academic Press, 1997. p. 198-217.

. A Study of the relationship between student learning and its academic context. 1981. Tese (Doutorado em Educação) - University of Lancaster, Lancaster.

RICKARDS, J. P.; FRIEDMAN, F. The Encoding versus the external storage hypothesis in note taking. Contemporary Educational Psychology, v. 3, n. 3, p. 136-143, 1978.

SNOW, R.; CORNO, L.; JACKSON, D. Individual differences in affective and conative functions. In: BERLINER, D. C.; CALFEE, R. C. (Eds.) Handbook of Educational Psychology. New York: MacMillan, 1996. p. 243-310.

STERNBERG, R. Thinking styles. New York: Cambridge University Press, 1997.

STERNBERG, R.; ZHANG, L. Styles of thinking as a basis of differentiated instruction. Theory into Practice, London, v. 44, n. 3, p. 245-253, 2005.

STRUYVEN, K.; DOCHY, F.; JANSSENS, S. Students' perceptions about evaluation and assessment in higher education: a review. Assessment and Evaluation in Higher Education, v. 30, n. 4, p. 325-341, Aug. 2005.

VILLAS BOAS, B. Avaliação no trabalho pedagógico universitário. In: CASTANHO, S.; CASTANHO, M. E. (Org.). O Que há de novo na educação superior: do projeto pedagógico à prática transformadora. Campinas: Papirus, 2000. p. 133-158.

Recebido em: outubro 2008

Aprovado para publicação em: maio 2009 